\title{
U⿱宀⿻三丨口
}

\section{Interpersonal polyvictimization and mental health in males}

Burns, C. R., Lagdon, S., Boyda, D., \& Armour, C. (2016). Interpersonal polyvictimization and mental health in males. Journal of Anxiety Disorders, 40, 75-82. https://doi.org/10.1016/j.janxdis.2016.04.002

Link to publication record in Ulster University Research Portal

\section{Published in:}

Journal of Anxiety Disorders

Publication Status:

Published (in print/issue): 01/05/2016

DOI:

10.1016/j.janxdis.2016.04.002

\section{Document Version}

Author Accepted version

\section{General rights}

Copyright for the publications made accessible via Ulster University's Research Portal is retained by the author(s) and / or other copyright owners and it is a condition of accessing these publications that users recognise and abide by the legal requirements associated with these rights.

\section{Take down policy}

The Research Portal is Ulster University's institutional repository that provides access to Ulster's research outputs. Every effort has been made to ensure that content in the Research Portal does not infringe any person's rights, or applicable UK laws. If you discover content in the Research Portal that you believe breaches copyright or violates any law, please contact pure-support@ulster.ac.uk. 


\section{Accepted Manuscript}

Title: Interpersonal polyvictimization and mental health in males

Author: Carol Rhonda Burns Susan Lagdon David Boyda Cherie Armour

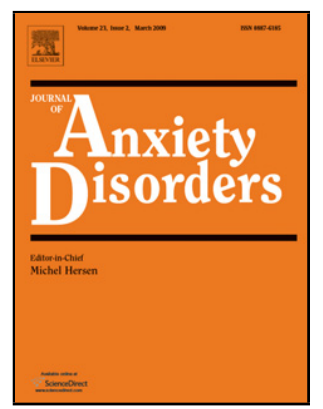

PII: S0887-6185(16)30048-2

DOI: http://dx.doi.org/doi:10.1016/j.janxdis.2016.04.002

Reference: ANXDIS 1826

To appear in: Journal of Anxiety Disorders

Received date: 19-2-2015

Revised date: $1-4-2016$

Accepted date:

3-4-2016

Please cite this article as: Burns, Carol Rhonda., Lagdon, Susan., Boyda, David., \& Armour, Cherie., Interpersonal polyvictimization and mental health in males.Journal of Anxiety Disorders http://dx.doi.org/10.1016/j.janxdis.2016.04.002

This is a PDF file of an unedited manuscript that has been accepted for publication. As a service to our customers we are providing this early version of the manuscript. The manuscript will undergo copyediting, typesetting, and review of the resulting proof before it is published in its final form. Please note that during the production process errors may be discovered which could affect the content, and all legal disclaimers that apply to the journal pertain. 
Running Head: Male victimization and mental health

\section{Highlights}

1. Four discrete polyvictimization profiles were identified in an exclusively male sample.

2. The largest profile was a non-victimization profile

3. A discrete profile indicating high levels of polyvictimisation was uncovered

4. Members of all victimization profiles were more likely to report meeting mental health diagnostic criteria compared to the non-victimization profile. 
Running Head: Male victimization and mental health

Running Head: Male victimization and mental health

\title{
Interpersonal polyvictimization and mental health in males
}

\author{
Carol Rhonda Burns
}

Susan Lagdon

David Boyda

Cherie Armour*

Author Affiliations:

${ }^{a}$ School of Psychology, University of Ulster, Coleraine, Northern Ireland, UK

Emails: $\mathrm{CA}=\underline{\text { armour.cherie@gmail.com }}, \mathrm{CRB}=\underline{\text { burns-cr@email.ulster.ac.uk, }}, \mathrm{SL}=\underline{\text { lagdon- }}$ $\underline{\text { s@email.ulster.ac.uk }}$ and DB = boyda-d1 @email.ulster.ac.uk

Word Count $=5811$

*Address correspondence to:

Cherie Armour, School of Psychology, University of Ulster, Coleraine, Northern Ireland, UK Email: armour.cherie@gmail.com; Phone: (0044) 02870123374. 


\begin{abstract}
A consistent conclusion within the extant literature is that victimization and in particular polyvictimization leads to adverse mental health outcomes. A large body of literature exists as it pertains to the association between victimisation and mental health in studies utilising samples of childhood victims, female only victims, and samples of male and female victims; less research exists as it relates to males victims of interpersonal violence. The aim of the current study was therefore to identify profiles of interpersonal victimizations in an exclusively male sample and to assess their differential impact on a number of adverse mental health outcomes. Using data from 14,477 adult males from Wave 2 of the NESARC, we identified interpersonal victimization profiles via Latent Class Analysis. Multinomial Logistic Regression was subsequently utilized to establish risk across mental health disorders. A 4class solution was optimal. Victimisation profiles showed elevated odds ratios for the presence of mental health disorders; suggesting that multiple life-course victimisation typologies exists, and that victimization is strongly associated with psychopathology. Several additional notable findings are discussed.
\end{abstract}

Keywords: Interpersonal victimisation; Polyvictimisation; Latent Class Analysis; Males; Mental Health; PTSD. 
Running Head: Male victimization and mental health

\section{Introduction}

Distress caused to a victim of maltreatment, irrespective of age, has the potential for a variety of long term catastrophic consequences on mental health. Indeed, childhood sexual abuse has been found to increase the likelihood of eating disorders (Rome, 2004) and victims of childhood physical abuse have an augmented likelihood of attention deficit hyperactivity disorder (ADHD), posttraumatic stress disorder (PTSD), and bipolar disorder (Sugaya et al., 2012). Adult victims of rape experience posttraumatic symptomology (Armour, Shevlin, Elklit \& Mroczek, 2012) and adult victims of physical violence report symptoms of both depression and anxiety (Golding, 1999). A consistent conclusion within the extant literature is that victimization leads to adverse mental health outcomes (cf. Finkelhor, Ormund, \& Turner, 2007; Lagdon, Armour, \& Stringer, 2014). In addition, cumulative exposures to traumatic experiences are known to increase the risk for mental health outcomes in a dose response fashion (Shevlin, Houston, Dorathy \& Adamson, 2008).

Of note, a number of prior studies have focused their attention on a single victimisation event (e.g., one of 'the big three'; sexual abuse, physical abuse, or neglect; Cuevas, Finklehor, Clifford, Ormrod \& Turner, 2009; Saunders, Kilpatrick, Hanson, Resnick \& Walker, 1999; Paolucci, Genuis, \& Violato, 2001; Pérez-Fuentes et al., 2013; Spataro, Mullen, Burgess, Wells \& Moss, 2004), victimisations which occur in childhood (e.g., witnessing domestic violence; Fantuzzo \& Mohr, 1999; Levendosky, Huth-Bocks, Semel \& Shapiro, 2002), adolescence (e.g., Romano, Bell, \& Billette, 2011), or adulthood (e.g., Lagdon, Armour, \& Stringer, 2014), and victimisations of females or mixed gender samples (e.g., Shevlin \& Elklit, 2008; Springer, Sheridan, Kuo \& Carnes 2007; Banyard et al., 2001; Edwards et al., 2003; Anda et al., 2006; Briere and Elliot, 2003). Thus, few studies have assessed victimisation and mental health outcome in an exclusively male sample. 
Running Head: Male victimization and mental health

The extant literature acknowledges that victimisations rarely occur as stand-alone entities (Finklehor, Ormund \& Turner, 2007; Higgins and McCabe, 2001; Pears, Kim, \& Fisher, 2008). Higgins and McCabe (2000) and Green et al. (2010) concluded that multiple forms of childhood abuse and neglect co-exist; they therefore suggested that victimisations should not be examined in isolation if a true picture of the nature, prevalence, and consequences are to be obtained. Notably, several studies have shown that where victimisation exists, polyvictimisation is common (Dong, Anda, Dube, Giles \& Feletti, 2003; Edwards, Holden, Felitti \& Anda 2003; Finkelhor, Turner, Hamby \& Ormrod, 2011; Higgins \& McCabe, 2000; Moller, Bachmann \& Moeller, 1993) and where polyvictimisation occurs, adverse mental health outcomes are highly prevalent (Bryant \& Range, 1995; Lagdon et al., 2014). Moreover, several recent studies have unanimously reported that where individuals are exposed to varying types of interpersonal victimisations, compared to the repeated exposure of a single victimisation, the impact on mental health is far more deleterious (Barnes, Noll, Putman \& Trickett, 2009; Cuevas et al., 2009; Finkelhor et al., 2007, 2009; Turner, Finkelhor \& Omrod, 2010).

Polyvictimisation experiences can occur both concurrently and longitudinally, thus cumulatively. Repeat victimization, when an additional victimisation occurs after a previous victimisation, “... at a much higher rate than chance factors can explain” (Skogan 1999, p. 44) is a common occurrence across many types of victimisation events. Armour and Sleath (2014) assessed retrospective reports of victimisations in childhood, adolescence, and adulthood in a large sample of Northern Irish students. It was found that witnessing severe violence in parental relationships when a child was associated with further victimisations during adolescence and adulthood, and that victimisation profiles comprising events from different stages of the life course related to adverse mental health outcomes. Other studies have demonstrated that childhood victims can be re-victimised and that cumulative trauma 
Running Head: Male victimization and mental health

exposure poorly affects mental health (Cavanagh et al., 2013; Desai et al., 2002; Shevlin, et al., 2007). Revictimisation has also been noted in cases of schoolyard bullying (Pitts \& Smith, 1995), sexual abuse (Classen et al., 2005), and intimate partner violence (Kuijpers, van der Knaap \& Winkel, 2012a).

In assessing and identifying the underlying mechanisms linking one victimisation to another, victimological theory has traditionally highlighted lifestyle factors such as proximity to perpetrators and risk-taking behaviours (Mustaine \& Tewksbury 1998; Sampson \& Lauritsen 1990). However, critics have suggested that these factors do not adequately address revictimisation particularly as it relates to interpersonal victimisations. More recently, researchers have begun to study psychological mechanisms. Indeed, it has been reported that the mental health outcomes of the initial victimisation may increase risk for subsequent victimisations, particularly in regard to PTSD. Furthermore, factors such as attachment and anger may also increase the risk of further victimisation (Kuijpers, van der Knaap \& Winkel, 2012a, 2012b).

In considering gender, prevalence rates of abuse experiences have been shown to differ in males compared to females (Shorey, Febres, Brasfield \& Stuart, 2012). Christoffersen, et al. (2013) reported that females endorsed higher rates of physical neglect, emotional abuse, and childhood sexual abuse compared to males. May-Cahal and Cawson (2005) reported that rates of childhood neglect, emotional maltreatment, and sexual abuse were elevated in female respondents; males however reported higher rates of physical violence. Several reasons have been put forward for this gender disparity including males being reluctant to disclose vulnerability (Maxfield \& Grande-Bretagne, 1984, cited in Stanko \& Hobdell, 1993), being embarrassed about the events, and / or feeling that they will be treated with scepticism on reporting victimisation experiences (Brown, 2004). Of note, the 
Running Head: Male victimization and mental health

mental health consequences of victimisations have also been shown to differ by gender (Dhinga, Boduszek \& Sharrat, 2015). McChesney, Adamson and Shevlin (2015) reported that trauma exposed males endorsed higher rates of drug and alcohol abuse disorders and trauma exposed females endorsed higher rates of axis 1 disorders. Peterson, Voller, Polusney and Murdoch (2011) noted that adult male victims of sexual abuse reported greater traumatic stress symptomology than females.

As noted, fewer studies have assessed maltreatment and victimisation in an exclusively male sample; with researchers suggesting that the field of trauma and victimisation on the whole is unequally weighted in the direction of female victimization with males appearing to be a forgotten group (Browning 2002; Dube et al., 2005). To our knowledge this is the first study which has assessed both childhood and adulthood interpersonal polyvictimisation profiles in an exclusively male sample and therefore the first to assess the impact of such profiles on subsequent mental health outcomes in males. We hypothesised that 1) several typologies of male interpersonal polyvictimisation would be uncovered (cf. Armour et al., 2014; Cavanagh et al., 2013; Dong et al., 2003; Edwards et al., 2003; Finkelhor et al., 2011; Higgins \& McCabe, 2000; Moller et al., 1993; Nooner et al., 2010), 2) one of these would be a normative typology (normative in that no or negligible levels of interpersonal victimisation would be reported) (cf. Armour et al., 2014; Cavanagh et al., 2013; Nooner at al., 2010), 3) another would be an interpersonal polyvictimization typology, comprising both childhood and adulthood experiences (cf. Armour et al., 2014; Higgins \& McCabe, 2000; Dong et al., 2003; Edwards et al., 2003; Finkelhor et al., 2011; Moller et al., 1993) and 4) that victimisation typologies with a greater degree of interpersonal victimisations would have increased odds of meeting the diagnostic criteria of mental health disorders such as PTSD and Generalised Anxiety Disorder when compared to a nonvictimisation profile/s in an exclusively male sample (Bryant \& Range, 1995; Boxer \& 
Running Head: Male victimization and mental health

Terranova, 2008; Cavanagh et al., 2013; Finkelhor et al., 2007; Lagdon et al., 2014). Of note, these hypotheses are based on a large body of literature from mixed gender samples and female only samples; however the novel component of the current study is the assessment of these hypotheses as they pertain to an exclusively male sample. 


\section{Method}

\subsection{Sample}

Study participants were drawn from National Epidemiologic Survey on Alcohol and Related Conditions (NESARC). Wave 1 of the NESARC was conducted in 2001 to 2002 in which, 43,093 participants completed interviews. Wave 2 was conducted in 2004 to 2005 , out of the 39,959 eligible respondents, 34,653 completed interviews. The target population was the civilian non-institutionalized population, 18 years and older, residing in households and group quarters. All NESARC data were weighted to reflect the survey's design characteristics and account for oversampling and adjustment for nonresponse across socio-demographics. Blacks, Hispanics, and adults aged $18-24$ were oversampled therefore a weight variable was utilized to make the sample representative of the population (Grant \& Dawson, 2006). Comprehensive details pertaining to all methods used in the survey are available elsewhere (Dawson, Stinson, Chou \& Grant, 2008; Grant et al., 2003; Grant, Kaplan, Shepard \& Moore, 2005). Only data from male participants ( $n$ $=14,564)$ were used in this study.

\subsection{Measures}

\subsubsection{Demographics:}

An extensive range of demographics were queried as part of the NESARC survey. In this study we choose to use ethnicity and SES (as indicated by food stamp receipt) within our analysis given these background variables are known to be associated with victimization experiences (Finkelhor et al., 2007; Finkelhor, Shattuck, Turner, Ormrod, \& Hamby, 2011; Kaslow \& Thompson, 2008). The original coding in the NESARC pertaining to ethnicity was (1) White, non-Hispanic (2) Black, non-Hispanic (3) American Indian/Alaska native (4) 
Running Head: Male victimization and mental health

Asian/Native Hawaiian/Other Pacific Islander, (5) Hispanic. In the current study we recoded this into a series of dummy variables in which Caucasian could be compared to (1) Black, non-Hispanic, (2) Hispanic and (3) other ethnic minority. Participants were asked if they had personally received food stamps in the past year: (0) No (1) Yes. We utilized 'Yes' responses on this categorical variable as an indicator of Low SES.

\subsubsection{Diagnostic assessment:}

All psychiatric diagnosis were made according to the Diagnostic and Statistical Manual of Mental Disorders, Fourth Edition (DSM-IV) using the Alcohol Use Disorder and Associated Disabilities Interview Schedule (AUDADIS-IV; Grant, Dawson \& Hasin, 2001). The AUDADIS-IV is a modern diagnostic interview that can be administered either by clinicians or lay interviewers (Grant, Harford, Dawson, Chou \& Pickering, 1995). As a fully structured diagnostic interview, the AUDADIS-IV is entirely standardized and relies on selfreport information from respondents. The AUDADIS-IV can record information about a variety of psychiatric disorders such as substance use disorders, mood disorders, general anxiety disorders (GAD), personality disorders, and PTSD etc. and captures information regarding their occurrence and lifetime status (i.e. past year, and lifetime).

For the current study we utilised the lifetime diagnostic variables provided within the dataset which were created by assessing the individual's responses to the AUDADIS-IV questions. Several of the diagnostic variables were used (i.e. major depressive and dysthymic episode, hypomanic and manic episode, panic and agoraphobia without a history of panic disorder, and social and specific phobia disorder) in order to create four new diagnostic composite variables (i.e. mania, depressive, panic, $\&$ social phobia disorders). The individual diagnostic variables of Generalised Anxiety Disorder and PTSD were used in this study. Details are below: 
Running Head: Male victimization and mental health

Depressive disorder: A composite measure of depression was created from two items i.e. "Life time diagnosis of Dysthymic disorder" and "Life time diagnosis of Major depressive disorder." A positive endorsement of one or both items was coded as: (1) Life time diagnosis, whereas negative endorsements on both were coded as (0) No diagnosis.

Manic episode: A new composite measure of mania was created by combining two items i.e. "Life time diagnosis of manic disorder" and "Life time diagnosis of Hypomanic disorder." A positive endorsement of one or both items was coded as: (1) Life time diagnosis, whereas negative endorsements on both were coded as (0) No diagnosis.

Panic episode: A generalised measure of panic disorder was created by combing two items i.e. "Panic disorder with Agoraphobia", "Agoraphobia without panic disorder". A positive endorsement of one or both items was coded as: (1) Life time diagnosis, whereas negative endorsements on both were coded as (0) No diagnosis.

Social Phobia: A composite measure of social phobia was created from two items i.e. "Life time diagnosis of Social phobia" and "Life time diagnosis of Specific phobia." A positive endorsement of one or both items was coded as: (1) Life time diagnosis, whereas negative endorsements on both were coded as (0) No diagnosis.

General Anxiety disorder: The life time diagnosis of generalised anxiety was assessed using the binary coded diagnostic variable present in the dataset: (1) Life time diagnosis, (0) No diagnosis.

PTSD: The lifetime diagnosis of PTSD was assessed using the binary coded diagnostic variable present in the dataset: (1) Life time diagnosis of PTSD, (0) No diagnosis.

\subsubsection{Childhood/Adolescent Victimization Assessments:}


Running Head: Male victimization and mental health

Childhood and adolescent victimizations were assessed using three dichotomous questions which asked respondents about experiences before the age of 18 by a parent or primary caregiver. These included if they had ever experienced (1) Childhood physical abuse, (2) Childhood neglect, and (3) Saw serious fights at home before age 18. All responses were coded as binary variables (1) Yes, (0) No.

\subsubsection{Life course / Adult Victimization Assessments:}

Victimizations were assessed using five dichotomous questions. Specifically, respondents were asked if they had ever experienced: (1) Sexual assault, rape or been molested, (2) Intimate partner violence, (3) Physical assault or beaten up, (4) If they had been stalked or (5) Experienced a threatening event such as being mugged, held up or threatened with a weapon. All responses were coded as follows: (1) Yes, (0) No. Items were taken from the trauma questionnaire in the PTSD diagnostic module. Note that the wording of some of these items, particularly the 'sexual assault, rape, or been molested' item allows for respondents to make an endorsement based on experiences that have occurred during childhood, adolescence, or adulthood (have you ever).

\subsection{Analytic Plan}

Missing data was assessed; if cases were missing more than $70 \%$ (6 endorsements) of the indicators to be included in the latent class analysis (LCA) they were removed from further analysis. In total $87(0.6 \%)$ cases were removed from the dataset resulting in a total sample size of 14,477 males for the analysis. A small proportion of the remaining cases $(n=38)$ were missing on either one or two victimization indicators. Mplus makes use of cases with incomplete data and missing data is estimated based on the values of the covariates in the model using full information maximum likelihood (Schafer \& Graham, 2002). Remaining missing data was treated in this manner in the current study. Analysis was conducted in two 
Running Head: Male victimization and mental health

steps. For the first step, LCA was utilized to determine victimization typologies and their prevalence using Mplus 7 (Muthén \& Muthén, 2013). A series of 2-6 models were specified and model selection was conducted according to a range of fit indices such as the Akaike Information Criteria (AIC: Akaike, 1987), the Bayesian Information Criterion (BIC: Schwarz, 1978), and the sample size adjusted BIC (SSABIC: Sclove, 1987). The standardized entropy value was used to indicate accuracy in participants' classification (values range from 0 to 1 ), with higher values indicating better classification. Optimal fitting models are indicated by lower values of the AIC, BIC and the SSABIC. Please note that due to the use of sampling weights for the NESARC data Mplus does not provide the bootstrapped LRT.

The second step was to assess the association between demographic variables (SES and ethnicity), the four latent classes, and psychiatric diagnoses. The ethnicity variable was dummy coded and Caucasian was used as a reference group in which to compare the other ethnic minorities. The latent classes were also coded as dummy variables based on their most likely class membership (MLCM). Class 1 which endorsed the lowest amounts of victimization was used as the reference class and only classes 2 - 4 were included as predictors in the final model to establish the association between class membership and the dependent variables (i.e. general anxiety, depressive, manic disorders, PTSD etc.) All analyses were conducted using Mplus 7 (Muthén \& Muthén, 2013) using robust maximum likelihood (Yuan \& Bentler, 2008).

\section{Results}

After accounting for missing data the effective sample size comprised 14,477 participants. Almost one third of respondents reported having at least one victimization experience in their life time. The descriptive statistics, frequencies and weighted percentages are shown in table 1 and table 2. 
Running Head: Male victimization and mental health

$* * *$ Table $1 \& 2$ about here***

The fit statistics for the LCA are presented in table 3. The four class solution was considered optimal for a number of reasons. The AIC measure improves as each of the classes is added but a large difference is experienced between classes 2 and 3 and successive smaller increments between classes 3 and 4, and 4 and 5. The BIC was lowest for the four class solution and the SSABIC shows a large improvement from classes 2 to 3 , a moderate improvement from classes 3 to 4 , however from classes 4 to 5 the improvement is minimal. The entropy level for each of the two through six classes shows clear classification with all results being in the region of 0.8 .

$* * *$ Table 3 about here***

As seen in figure 1, latent class 1 is characterised by low positive endorsement on all indicators of interpersonal victimisation across the life course and is the largest class with $81.4 \%(n=12,736)$ of the sample belonging to this group. Conversely, latent class 4 had the smallest group membership with $2.1 \%(n=237)$ of the sample belonging to this group. This class positively endorse high levels of victimisation on all indicators across the life course, relative to alternative classes. Latent class 2 consisted of $4.5 \%(n=569)$ of the sample. Relative to other classes, this class is characterised by moderate endorsement of childhood physical abuse, childhood neglect, other physical abuse (attacked, beaten), and threatening event (mugged, or threatened with a weapon) but a very high positive endorsement of witnessing domestic violence in childhood. Latent class 3 comprised $12 \%(n=936)$ of the sample. This class, relative to others, is characterised by having low endorsements across most victimisation variables but high endorsements on the measures of other physical assault such as being beaten up, being mugged, or being threatened with a weapon in adulthood. 
The observed results from the logistic regression revealed significant associations for all classes compared to the reference class; class 1 (Please see Table 4 for all odds ratios (OR's) and confidence intervals (CI's)). The OR's for class 2, in which participants had the highest probability of being witness to domestic violence and moderate probabilities of reporting childhood physical abuse and neglect, ranged from $2.0-4.3$ respectively. The observed results for class 3 , in which participants had a high probability of endorsing physical assault (attacked or beaten) and other forms of assault (mugged or threatened with a weapon) also demonstrated high odds ratios compared to the baseline class; these ranged from 2.4 - 5.6 in magnitude. Excluding 'being witness to domestic violence', class 4 endorsed the highest number of victimization experiences and demonstrated high odds ratios across all victimization indicators compared to the reference class; these ranged from $3.4-12.5$ in magnitude. The observed results for low socio-economic status to all measures of psychopathology were significant with odds ratios ranging from $1.63-2.88$ in magnitude.

$$
* * * \text { Table } 4 \text { about here } * * *
$$

\section{Discussion}

The current study examined whether distinct typologies of interpersonal victimisation across the life course are found in an exclusively male sub-sample of a population based survey of adult Americans. We further assessed whether individuals classified into victimization typologies comparted to a baseline (no/low victimisations) typology conferred greater risk for negative mental health outcomes. It was hypothesised based on prior literature that 1) several typologies of interpersonal victimisation would be uncovered, 2) one of these would be a normative typology, 3) another would be an interpersonal polyvictimization 
Running Head: Male victimization and mental health

typology, comprising both childhood and adulthood experiences, and 4) that victimisation typologies with a greater degree of interpersonal victimisations would have increased odds of meeting the diagnostic criteria of mental health disorders such as PTSD and Generalised Anxiety Disorder when compared to non-victimisation profiles (Cavanagh et al., 2013; Dong et al., 2003; Edwards et al., 2003; Finkelhor et al., 2011; Higgins \& McCabe, 2000; Lagdon et al., 2014; Nooner at al., 2010). All hypotheses were supported.

Of considerable concern is the finding that $32.2 \%$ of the entire sample positively endorsed at least one of the interpersonal victimisation indicators, as seen in Table 2. This equates to 4,660 participants, demonstrating that the victimisation of males is a significant social concern for both policy makers and researchers alike. As hypothesised, the LCA identified multiple distinct victimization typologies. Latent class 1 was labelled as the 'normative class', and showed low or no endorsements of victimisation indicators across the life course. This class constituted the majority of participants, $(n=12,736 ; 81.4 \%)$ and is commensurate with results from other studies (Armour et al., 2014; Cavanagh et al., 2013; Nooner et al., 2010; McChesney et al., 2015) which have uncovered non-victimisation typologies; however none were conducted exclusively with male participants.

Latent class 2 is characterised by very high endorsement of witnessing domestic violence during childhood and moderate endorsement on all other indicators except intimate partner violence (IPV), which was negligible. This class was labelled as the 'high witnessing of domestic violence \& polyvictimisation class' and comprised 596 cases (4.5\%). The identification of this class supports the assertion that males, similar to females and mixed gender samples, experience multiple interpersonal victimizations and that these occur throughout the life course; thus in both childhood and adulthood. An interesting point to note as it relates to members of class 2 is the high endorsement of witnessing domestic violence during childhood yet the low endorsement of IPV. Prior research has suggested that 
Running Head: Male victimization and mental health

witnessing IPV in childhood increases the risk for being a victim of IPV in adulthood (Hamby, Finkelhor, Turner, \& Ormrod, 2010) however this does not appear to be the case for individual represented in class 2. One potential explanation for this can be found in Armour and Sleath (2014) who reported similar findings and suggested that witnessing severe IPV in childhood may in fact reduce the likelihood of IPV victimisation in later life. This premise stems from social learning theory (Bandura, 1973, 1977) which proposes that children not only model their behaviour on direct observations but also through perceptions of the behaviours consequences (positive or negative). If children observe IPV as having negative consequences this may in fact deter such involvement in such behaviours in adulthood.

Latent class 3 is characterised by low or no endorsement of the childhood indicators but an elevated endorsement of adult interpersonal victimisation indicators and as such has been labelled 'adult victimisation'. Indeed, relative to other indicators, individuals in this adult victimisation class demonstrated moderate probabilities of endorsing the experience of being stalked and high probabilities of endorsing both experiences of physical assault. This signifies that a particular group of males experience interpersonal victimisations later in life with the absence of victimisations in childhood. We speculate that this may be attributable to young males reaching adulthood and becoming involved in environments that encourage aggression and violence thus in turn may also increase the risk of violent victimisations (Fox, Rufino \& Kercher, 2012; Howell, 2010).

The final class; class 4 , is characterised by a high positive endorsement of all the interpersonal victimisation indicators. This 'childhood and adulthood polyvictimisation class' is composed of $2.1 \%(n=237)$ of the population. With the exception of witnessing domestic violence in childhood (highest probabilities in class 2), this class demonstrated the highest probabilities across all indicators. These findings are similar to those reported by Ogloff, Cutajar, Mann, and Mullen (2012), who conducted a forty five year follow up study of 2,759 
Running Head: Male victimization and mental health

child sexual abuse victims in which males who had experienced childhood sexual abuse were more likely to experience adult victimization of violent crimes. Although current findings are based on a small percentage of the sample, it is worth noting that a significant relationship between male childhood sexual abuse and adult re-victimization exists.

In assessing how each of the resultant profiles related to mental health diagnoses whilst controlling for socio-economic status and ethnicity, those individuals in victimisation typologies (classes $2,3,4$ ) were significantly more likely to meet the diagnostic criteria of mental health disorders (GAD, Depressive disorder, Manic disorder, Panic disorder, Social Phobia, and PTSD) when compared to the normative typology (class1). Those who were deemed to be of low SES (by being in receipt of food stamps) were more likely to meet the criteria for all of the assessed mental health outcomes (see table 4 for OR's \& CI's). These findings support those of previous studies (e.g., Williams, Yu, Jackson \& Anderson, 1997; Goodman, Pugach, Skolnik \& Smith, 2013).

In relation to ethnicity, the current study revealed that those self-reporting their ethnicity as Black, Hispanic, or other compared to Caucasian demonstrated a general pattern of being less likely to meet diagnostic criteria across a range of disorders (see table 4 for OR's \& CI's). Previous studies have reported mixed findings in regard to whether or not minority ethnicity is a risk factor for psychopathology (Huang et al., 2006; Smith et al., 2006). Of note however, previous research utilizing the NESARC reported that individuals self-reporting as Black, Hispanic or Asian were less likely to report psychopathology if they had higher scores on a measure of ethnic identity. The researchers proposed that a sense of pride, belonging, and attachment to one's racial/ethnic group may be the factors which protect against psychopathology (Burnett-Zeigler, Bohnert, \& Ilgen, 2013). Given we also utilised the NESARC data for the current study it is feasible that these same factors may be protective 
Running Head: Male victimization and mental health

for psychopathology subsequent to male interpersonal victimisation; note however that we did not assess levels of ethnic identity within the profiles.

Considering mental health, Class 2, the 'high witnessing of domestic violence and polyvictimisation class' reported an increased likelihood of all the assessed mental health disorders with odd ratios ranging from 2.0 to 4.38 (see Table 4). Cavanagh et al. (2013), in their exclusively female sample, found a similar latent class to our class 2 which reported the greatest mean scores for past year mental health disorders. Therefore, there may be some unique pathways to mental health disorders when children are exposed to witnessing domestic violence in combination with the experience of alternative childhood victimisations (cf. Anda et al., 2006; Osofsky, 1995; Russell, Springer \& Greenfield, 2010). Compared to the reference class, those in the 'adult victimisation' class (class 3) were also more likely to meet the diagnostic criteria for a wide range of psychiatric diagnoses, indicating that victimisation in adulthood alone still result in deleterious effects on an individual's mental health.

Finally, latent class 4, the 'childhood and adulthood polyvictimisation class' reported an increased likelihood of all the assessed mental health disorders; with odd ratios ranging from 3.44 to 12.56 (see Table 4). One of the most pronounced findings were that members of class 2 were 12 times more likely to meet the criteria for PTSD compared to those in the non-victimisation reference class. Given that members of this class reported the highest probabilities of endorsement across the majority of interpersonal victimisations this is unsurprising. Indeed, the probabilities associated with members of class 4 meeting the diagnostic criteria across all disorders were extremely high relative to the probabilities associated with members of classes 2 and 3 . These findings demonstrate the severe risk posed by cumulative victimisations across the life course in male victims. Of particular note, members of this class had a high probability of reporting a sexual abuse experience relative to 
Running Head: Male victimization and mental health

members of alternative classes. To date much of the existing literature has focused on female victims of childhood sexual abuse (CSA). In turn, more is known about the adverse consequences of female sexual assault than what is known about the adverse consequences of male sexual assault (Dhaliwal, Gauzas, Antonowicz \& Ross, 1996). The current study's findings suggest that males are at great risk of adverse mental health outcomes as a result of multiple victimisations, particularly when this includes childhood sexual assault.

The above findings support the notion that psychological outcomes are related to cumulative nature of abuse and victimisations (Scott-Storey, 2011). As discussed earlier, victimisation is rarely a standalone event, rather an enduring process with a multifinality of outcomes. Humphreys et al. (2005) argued that the focus should not be on individual types of maltreatment, but on the cumulative effects. With reference to latent classes 2,3 , and in particular 4 in the current study, victimisation in any one form appears to have the potential to increase an individuals vulnerability to re-victimisation (Finkelhor et al., 2007; Boxer \& Terranova, 2008). Moreover, the cumulative effects of those victimisations have a significant impact on a male victim's mental health (Scott-Storey, 2011; Banyard et al., 2001; Campbell, Greeson, Bybee \& Raja, 2008).

The current study is not without limitation. The NESARC data is collected retrospectively by self-report and as such may be subject to recall bias. Of note, however, many studies of victimisation in childhood are retrospective accounts of childhood experiences by adult respondents. Armour et al. (2014) asked Danish 24 year olds to recall childhood abuse experiences and Vogeltanz, Wilsnack, Harris et al. (1999) asked adult females to retrospectively report their experiences of sexual abuse in childhood. A further limitation is that victimisation experiences are queried only by whether an event ever occurred; no consideration was given to intensity, frequency, or duration of the victimizations. It is also possible that a small number of cases reporting PTSD are doing so 
Running Head: Male victimization and mental health

due to experiences which were not interpersonal victimisations and thus not included in our LCA, for example those of natural disaster and combat. However these people would be present in the normative profile unless they had also reported alternative interpersonal victimisations across their life-course. Importantly, we are not aware of a single study which has profiled interpersonal victimisations across the life course in an exclusively male sample and therefore nor are we aware of a study which has assessed the impact of these victimisation profiles on mental health. Finally, it is important to note that the NESARC diagnostic variables are based on DSM-IV criteria and not on the more recent DSM-5 criteria.

\subsection{Conclusions}

In summary, the current study found four distinct latent profiles when assessing interpersonal victimisation over the life-course in a male only sample. One normative profile characterised by low or no victimisation experiences and three victimisation profiles of differing characteristics showing elevated risk of psychopathology. Understanding how interpersonal victimisations co-occur across the life course in male victims and how this relates to psychopathology has many implications. It will inform questions asked by clinicians when presented with a male survivor of victimisation. It will also help to identify which victims may be at increased risk of further victimisation across their life course. Further investigation of risk and resilience factors and mediating and moderating variables would be of great value. We know that polyvictimisation is prevalent and being a victim increases the likelihood of further victimisation and ultimately of psychopathology. Therefore it is pertinent that those who deliver primary services to victims should be cognisant of the differing victimisation profiles specific to men and the impact that such may be having on their psychological well-being. Increasing the knowledge base related to the psychological impact of life-course interpersonal victimisations in males is fundamentally important to 
Running Head: Male victimization and mental health

ensure that services are developed to meet the needs of these male victims. Future research may wish to extend this analytical framework by including a range of non-interpersonal traumas within their latent class models.

Acknowledgements: There are no acknowledgements associated with this work. 


\section{References}

Akaike, H. (1987). Factor analysis and AIC. Psychometrika, 52(3), 317-332.

Anda, R. F., Felitti, V. J., Bremner, J. D., Walker, J. D., Whitfield, C. H., Perry, B. D., Dube, S.R., \& Giles, W. H. (2006). The enduring effects of abuse and related adverse experiences in childhood. European archives of psychiatry and clinical neuroscience, 256(3), 174-186.

Armour, C., Elklit, E., \& Christoffersen, M.N. (2014) A Latent Class Analysis of Childhood Maltreatment: Identifying Abuse Typologies, Journal of Loss and Trauma: International Perspectives on Stress \& Coping, 19:1, 23-39,

Armour, C., Shevlin, M., Elklit, A., \& Mroczek, D. (2012) A Latent Growth Mixture Modeling Approach to PTSD Symptoms in Rape Victims. Traumatology 18 (1): 20 $\underline{28}$

Bagley, C., \& Ramsey, R. (1986) Sexual Abuse in Childhood: Psychosocial Outcomes and Implications for Social Work Practice. Journal of Social Work \& Human Sexuality 4, $1-2$.

Barnes, J. E., Noll, J. G., Putnam, F. W., \& Trickett, P. K. (2009). Sexual and physical revictimization among victims of severe childhood sexual abuse. Child Abuse and Neglect, 33, 412-20.

Banyard, V. L., Williams, L. M., \& Siegel, J. A. (2001). The long-term mental health consequences of child sexual abuse: An exploratory study of the impact of multiple traumas in a sample of women. Journal of traumatic stress, 14(4), 697-715.

Black, M.C., Basile, K.C., Breiding, M.J., Smith, S.G., Walters, M.L., Merrick, M.T., Chen, J., \& Stevens, M.R. (2011). The National Intimate Partner and Sexual Violence Survey (NISVS): 2010 Summary Report. Atlanta, GA: National. Center for Injury Prevention and Control, Centers for Disease Control and Prevention.

Bolger, K. E., \& Patterson, C. J. (2001). Developmental pathways from child maltreatment to peer rejection. Child Development, 72(2), 549-568.

Boxer, P., \& Terranova, A.M. (2008) Effects of multiple maltreatment experiences among psychiatrically hospitalized youth. Child Abuse \& Neglect 32 (6):637 - 647

Briere, J., \& Elliot, D.M. (2003) prevalence and psychological sequelea of self-reported childhood physical and sexual abuse in a general population sample of men and women, Child Abuse \& Neglect. 27(10): 1205-1222

Brogden, M. Niljhar S. (2004) Abuse of Adult Males in Intimate Partner Relationships in Northern Ireland. 
Running Head: Male victimization and mental health

Browning, C. R. (2002) Trauma or transition: A life-course perspective on the link between childhood sexual experiences and men's adult well-being. Social Science Research 31: 473-510

Bryant, S. L., \& Range, L. M. (1995). Suicidality in college women who were sexually and physically abused and physically punished by parents. Violence and Victims, 10, 195201 Burnett-Zeigler, I., Bohnert, K. M., \& Ilgen, M. A. (2013). Ethnic identity, acculturation and the prevalence of lifetime psychiatric disorders among Black, Hispanic, and Asian adults in the US. Journal of $\mid$ Psychiatric Research, 47(1), 56-63.

CAADA (2014). In plain sight: The evidence from children exposed to domestic abuse. CAADA Research Report. February, 2014.

Campbell, R., Greeson, M. R., Bybee, D., \& Raja, S. (2008). The co-occurrence of childhood sexual abuse, adult sexual assault, intimate partner violence, and sexual harassment: a mediational model of posttraumatic stress disorder and physical health outcomes. Journal of consulting and clinical psychology, 76(2), 194.

Cavanagh, C. E., Martins, S., Petras, H., \& Campbell, J.C. (2013) Mental Disorders Associated with Subpopulations if Women Affected by Violence and Abuse. Journal of Traumatic Stress, 26, 459-466.

Chen, C.M., Yi, H-y., Dawson, D.A., Stinson, F.S., Grant, B.F., \& Breslow, P. (2010) The Alcohol Epidemiologic Data System (AEDS) for the Division of Epidemiology and Prevention Research (DEPR) of the National Institute on Alcohol Abuse and Alcoholism (NIAAA), National Institutes of Health (NIH), U.S. Department of Health and Human Services. NIH Publication No. 10-7677

Christoffersen, M.N., Armour, C., Lasgaard, M., Andersen, T. E., \& Elklit, A. (2013) The Prevalence of Four Types of Childhood Maltreatment in Denmark. Clinical Practice \& Epidemiology in Mental Health, 2013, 9, 149-156

Collins, L. M., Fidler, P. L., Wugalter, S. E., \& Long, J. D. (1993). Goodness-of-fit testing for latent class models. Multivariate Behavioral Research, 28(3), 375-389.

Cuevas, C. A., Finkelhor, D., Ormrod, R. K., Turner, H. A. (2008). Psychiatric Diagnosis as a Risk Marker for Victimization in a National Sample of Children. Journal of Interpersonal Violence, 24, 636-652

Dawson, D. A., Stinson, F. S., Chou, S. P., \& Grant, B. F. (2008). Three-year changes in adult risk drinking behavior in relation to the course of alcohol-use disorders. Journal of Studies on Alcohol and Drugs, 69(6), 866-877.

Desai, S., Arias, I., Thompson, M. P., \& Basile, K. C. (2002). Childhood victimization and subsequent adult revictimization assessed in a nationally representative sample of women and men. Violence and Victims.Dhaliwal, G.K., Gauzas, L., Antonowicz, D.H., \& Ross, R.R. (1996). Adult male survivors of childhood sexual abuse: 
Running Head: Male victimization and mental health

Prevalence, sexual abuse characteristics, and long-term effects. Clinical Psychology Review, 16(7), 619-639.

Dhingra, K., Boduszek, D., \& Sharratt, K. (2015). Victimization profiles, non-suicidal selfinjury, suicide attempt, and post-traumatic stress disorder symptomology: application of latent class analysis. Journal of Interpersonal Violence. ISSN 0886-2605 (In Press)

Dong, M., Anda, R. F., Dube, S. R., Giles, W. H., \& Felitti, V. J. (2003). The relationship of exposure to childhood sexual abuse to other forms of abuse, neglect, and household dysfunction during childhood. Child abuse \& neglect, 27(6), 625-639

Draucker, C.B, \& Martsolf, D.S., (2010). Life Course Typology of Adults Who Experienced Sexual Violence. J Interpers Violence. 2010 July; 25(7): 1155-1182. doi:10.1177/0886260509340537

Dube, S. R., Anda, R. F., Whitfield, C. L., Brown, D. W., Felitti, V. J., Dong, M., \& Giles, W. H. (2005). Long-term consequences of childhood sexual abuse by gender of victim. American journal of preventive medicine, 28(5), 430-438.

Edwards, V. J., Holden, G. W., Felitti, V. J., \& Anda, R. F. (2003). Relationship between multiple forms of childhood maltreatment and adult mental health in community respondents: results from the adverse childhood experiences study. American Journal of Psychiatry, 160(8), 1453-1460.

Finkelhor, D., Hotaling, G., Lewis, I., \& Smith, C. (1990). Sexual abuse in a national survey of adult men and women: Prevalence, characteristics, and risk factors. Child abuse \& neglect, 14(1), 19-28.

Finkelhor, D., Ormrod, R. K., \& Turner, H. A. (2007). Poly-victimization: A neglected component in child victimization. Child Abuse \& Neglect, 31, 7-26.Finkelhor, D., Ormrod, R. K., \& Turner, H. A. (2007). Polyvictimization and Trauma in a National Longitudinal Cohort. Development and Psychopathology, 19(01), 149-166. doi:10.1017/S0954579407070083

Finkelhor, D., Turner, H., Hamby, S. And Ormrod, R., (2011). Polyvictimization: Children's Exposure to Multiple Types of Violence, Crime, and Abuse. Juvinlile Justice Bulliten, October 2001. US Department of Justice.

Finkelhor, D., Shattuck, A., Turner, H. A., Ormrod, R., \& Hamby, S. L. (2011). Polyvictimization in Developmental Context. Journal of Child \& Adolescent Trauma, 4(4), 291-300. doi:10.1080/19361521.2011.610432

Finkelhor, D., Turner, H., Hamby, S., \& Ormrod, R. (2014). Polyvictimization: Children's exposure to multiple types of violence, crime, and abuse. Free Inquiry in Creative Sociology, 39(2), 24-34.

Fox , K.A., Rufino, K.A. \& Kercher, G.A. (2012) Crime Victimization among Gang and Nongang Prison Inmates: Examining Perceptions of Social Disorganization, Victims 
Running Head: Male victimization and mental health

\& Offenders: An International Journal of Evidence-based Research, Policy, and Practice, 7:2, 208-225

Gadd, D., Farrall, S., Lombard, N., \& Dallimore, D. (2002) Domestic Abuse against Men in Scotland, Scottish Executive: Edinburgh.

Gershon, A., Minor, K., \& Hayward, C. (2008). Gender, victimization, and psychiatric outcomes. Psychological Medicine, 38(10), 1377-1391.

Golding, J. M. (1999). Intimate partner violence as a risk factor for mental disorders: A metaanalysis. Journal of Family Violence, 14(2), 99-132.

Goodman, L. A., Pugach, M., Skolnik, A., \& Smith, L. (2013). Poverty and Mental Health Practice: Within and Beyond the 50-Minute Hour. Journal of $\backslash$ Clinical Psychology, 69(2), 182-190.

Grant, B.F.; Harford T.C.; Dawson, D.A.; Chou, S.P., \& Pickering, R. (1995) The Alcohol Use Disorder and Associated Disabilities Interview Schedule (AUDADIS): Reliability of alcohol and drug modules in a general population sample. Drug and Alcohol Dependence 39(1):37-44.

Grant, B. F., Dawson, D. A., \& Hasin, D. S. (2001). The alcohol use disorder and associated disabilities interview schedule-DSM-IV version. Bethesda, MD: National Institute on Alcohol Abuse and Alcoholism.

Grant, B. F., Dawson, D. A., Stinson, F. S., Chou, P. S., Kay, W., \& Pickering, R. (2003). The Alcohol Use Disorder and Associated Disabilities Interview Schedule-IV (AUDADIS-IV): reliability of alcohol consumption, tobacco use, family history of depression and psychiatric diagnostic modules in a general population sample. Drug and Alcohol Dependence, 71(1), 7-16.

Grant, B. F., Kaplan, K., Shepard, J., \& Moore, T. (2005). Source and accuracy statement for wave 1 of the 2001-2002 National Epidemiologic Survey on Alcohol and Related Conditions. Bethesda, MD: National Institute on Alcohol Abuse and Alcoholism.

Grant, B. F., \& Dawson, D. A. (2006). Introduction to the national epidemiologic survey on alcohol and related conditions. Alcohol Health \& Research World, 29(2), 74.

Grant, B. F., Stinson, F. S., Dawson, D. A., Chou, S. P., Ruan, W. J., \& Pickering, R. P. (2004). Co-occurrence of 12-month alcohol and drug use disorders and personality disorders in the United States: results from the National Epidemiologic Survey on Alcohol and Related Conditions. Archives of General Psychiatry, 61(4), 361-368.

Gratz, K. L.. \& Chapman, A. L. (2007) The role of emotional responding and childhood maltreatment in the development and maintenance of deliberate self-harm among male undergraduates. Psychology of Men \& Masculinity, Vol 8(1): 1-14

Green, J. G., McLaughlin, K. A., Berglund, P. A., Gruber, M. J., Sampson, N. A., Zaslavsky, A. M., \& Kessler, R. C. (2010). Childhood adversities and adult psychiatric disorders 
Running Head: Male victimization and mental health

in the national comorbidity survey replication I: Associations with first onset of SMIV disorders. Archives of General Psychiatry, 67, 113-123.

doi:10.1001/archgenpsychiatry.2009.186

Hagenaars, J. A., \& McCutcheon, A. L. (2002). Applied latent class analysis. Cambridge, England: Cambridge University Press.

Hanson, R.K., \& Slater, S. (1988) Sexual Victimization in the History of Sexual Abusers: A Review. Sex Abuse 1: 485. DOI: 10.1177/107906328800100402

Higgins, D. J., \& McCabe, M. P. (2000). Multi-type maltreatment and the long-term adjustment of adults. Child Abuse Review, 9, 6-18.

Hines, D. A., \& Douglas, E. M. (2011). Symptoms of posttraumatic stress disorder in men who sustain intimate partner violence: A study of helpseeking and community samples. Psychology of men \& masculinity, 12(2), 112.

Houston, E., \& McKirnan, D. J. (2007). Intimate partner abuse among gay and bisexual men: Risk correlates and health outcomes. Journal of Urban Health, 84(5), 681-690.

Howell, J. C. (2010). Gang prevention: An overview of current research and programs. Juvenile Justice Bulletin.

Huang, B., Grant, B.F., Dawson, D.A., Stinson, F.S., Chou, S.P., Saha, T.D. \& Pickering, R.P. (2006). Race-ethnicity and the prevalence and co-occurrence of Diagnostic and Statistical Manual of Mental Disorders, alcohol and drug use disorders and Axis I and II disorders: United States, 2001 to 2002. Comprehensive Psychiatry, 47(4), 252-257.

Humphreys, J., Sharps, P. W., \& Campbell, J. C. (2005). What we know and what we still need to learn. Journal of interpersonal violence, 20(2), 182-187.

Kaslow, N. J., \& Thompson, M. P. (2008). Associations of Child Maltreatment and Intimate Partner Violence with Psychological Adjustment Among Low Ses, African American Children. Child Abuse \& Neglect, 32(9), 888-896. doi:10.1016/j.chiabu.2007.09.012

Kaur, R., \& Garg, S. (2008). Addressing domestic violence against women: An unfinished agenda. Indian Journal of Community Medicine: Official Publication of Indian Association of Preventive \& Social Medicine, 33(2), 7376. doi: 10.4103/09700218.40871.

Kendall-Tackett, K. A. (2000). Physiological correlates of childhood abuse: chronic hyperarousal in PTSD, depression and irritable bowel syndrome. Child Abuse \& Neglect, 24, $799-810$.

Lagdon, S., Armour, C., \& Stringer, M. (2014) Adult experience of mental health outcomes as a result of intimate partner violence victimisation: a systematic review. European Jourmal of Psychotraumatology. 2014, 5: 24796 
Running Head: Male victimization and mental health

Lo, Y. (2001). Testing the number of components in a normal mixture. Biometrika, 88(3), 767-778.

MacMillan, H.L., Fleming, J.E., Trocmé, N., Boyle, M.H., Wong, M., Racine, Y.A., Beardslee, W.R., \& Offord, D.R. (1997). Prevalence of Child Physical and Sexual Abuse in the Community; Results from the Ontario Health Supplement. The Journal of the American Medical Association.1997; 278: 131-135

McChesney, G. C., Adamson, G., \& Shevlin, M. (2015). Service use patterns and mental health symptoms among adolescents exposed to multiple types of trauma. Journal of Adolescence, 40, 1-10

May-Chahal, C., \& Cawson, P. (2005) Measuring child maltreatment in the United Kingdom: A study of the prevalence of child abuse and neglect. Child Abuse Neglect, 29: 96984.

Miller, W. B. (1958). Lower class culture as a generating milieu of gang delinquency. Journal of social issues, 14(3), 5-19.

Mohr, W. K., Lutz, M. J. N., Fantuzzo, J. W., \& Perry, M. A. (2000). Children Exposed to Family Violence A Review of Empirical Research from a Developmental-Ecological Perspective. Trauma, Violence, \& Abuse, 1(3), 264-283.

Moller, P.M., Bachmann, G.A., \& Moeller, J.R. (1993) The combined effects of physical, sexual, and emotional abuse during childhood: Long-term health consequences for women. Child Abuse \& Neglect. 17, 623-640

Muthén, B.O., \& Muthén, L.K. (2000) The development of heavy drinking and alcoholrelated problems from ages 18 to 37 in a US national sample. Journal of Studies on Alcohol and Drugs .61(2): 290-300

Muthén, L. K., \& Muthén, B. O. (2007). Mplus: Statistical Analysis with Latent Variables; User's Guide;[Version 5]. Muthén \& Muthén.

Muthén, L., \& Muthén, B. (2013). Mplus: Statistical analysis with latent variables: User's guide. Los Angeles, CA: Muthén \& Muthén.

Nooner, K. B., Litrownik, A. J., Thompson, R., Margolis, B., English, D. J., Knight, E. D., Everson. N. D., \& Roesch, S. (2010). Youth self-report of physical and sexual abuse: A latent class analysis. Child abuse \& neglect, 34(3), 146-154.

Nylund, K. L., Asparouhov, T., \& Muthén, B. O. (2007). Deciding on the number of classes in latent class analysis and growth mixture Modeling: AMonte Carlo simulation study. Structural Equation Modeling: A Multidisciplinary Journal, 14, 535-569.

Osofsky, J. D. (1995). The effect of exposure to violence on young children. American Psychologist, 50(9), 782. 
Running Head: Male victimization and mental health

Ozbay, F., Johnson, D. C., Dimoulas, E., Morgan III, C. A., Charney, D., \& Southwick, S. (2007). Social support and resilience to stress: from neurobiology to clinical practice. Psychiatry (Edgmont), 4(5), 35.

Palarea, R. E., Zona, M. A., Lane, J.C., \& Langhinrichsen-Rohling. J. (1999) The dangerous nature of intimate relationship stalking: threats, violence, and associated risk factors. Behavioural Science and the Law. 17(3):269-83.

Paolucci, E.O., Genuis, M.L., Violato, C. (2001). A meta-analysis of the published research on the effects of child sexual abuse. The Journal of Psychology,135(1), 17-36

Pérez-Fuentes, G., Olfson, M., Villegas, L., Morcillo, C., Wang, S., \& Blanco, C. (2013). Prevalence and correlates of child sexual abuse: a national study. Comprehensive psychiatry, 54(1), 16-27.

Peterman, A., Palermo, T., \& Bredenkamp, C. (2011) Estimates and Determinants of Sexual Violence Against Women in the Democratic Republic of Congo. American Journal of Public Health. 101(6): 1060-1067.

Robinson, L., \& Segal, J. (2013) Help for Abused Men. Helpguide.org. Retrieved October 30, 2013 from http://www.helpguide.org/mental/domestic-violence-menabused-by-women.htm

Rome, E. S. (2004). Eating disorders: uncovering a history of childhood abuse?. Epidemiology, 15(3), 262-263.

Russell, D., Springer, K. W., \& Greenfield, E. A. (2010). Witnessing domestic abuse in childhood as an independent risk factor for depressive symptoms in young adulthood. Child Abuse \& Neglect, 34(6), 448-453.

Saunders, B.E., Kilpatrick, D.G., Hanson, R.F., Resnick, H.S., Walker, M.E.(1999). Prevalence, Case Characteristics, and Long-Term Psychological Correlates of Child Rape among Women: A National Survey. Child Maltreatment, 4(3),187-200

Schwarz, G. (1978). Estimating the Dimension of a Model. The Annals of Statistics, 6(2), 461-464.

Sclove, S. L. (1987). Application of model-selection criteria to some problems in multivariate analysis. Psychometrika, 52(3), 333-343.

Scott-Storey, K. (2011). Cumulative abuse: do things add up? an evaluation of the conceptualization, operationalization, and methodological approaches in the study of the phenomenon of cumulative abuse. Trauma, Violence, \& Abuse, 12(3), 135-150.

Shevlin, M., \& Elklit, A. (2008). A latent class analysis of adolescent adverse life events based on a Danish national youth probability sample. Nordic Journal of Psychology, $62,218-224$. 
Running Head: Male victimization and mental health

Shorey, R.C., Febres, J., Brasfield, H., \& Stuart, G.L.. (2012) Male Dating Violent Victimization and Adjustment: The Moderating Role of Coping. American Journal of Men's Health.6(3) 218-22

Siegel, D. J. (1999). The developing mind (Vol. 296). New York: Guilford Press.

Smith, S.M., Stinson, F.S., Dawson, D.A., Goldstein, R., Huang, B., \& Grant, B. F. (2006). Race/ethnic differences in the prevalence and co-occurrence of substance use disorders and independent mood and anxiety disorders: Results from the National Epidemiologic Survey on Alcohol and Related Conditions. Psychological Medicine, 36(07), 987-998.

Springer, K. W., Sheridan, J., Kuo, D., \& Carnes, M. (2007). Long-term physical and mental health consequences of childhood physical abuse: Results from a large populationbased sample of men and women. Child Abuse \& Neglect, 31, 517-530.

Stanko, E. A., \& Hobdell, K. (1993). Assault on men. Masculinity and Male Victimization. British Journal of Criminology, 33(3), 400-415.

Stephenson, C. (2009). Fathers' experiences of domestic violence and their views on services for them and their children. A dissertation submitted to the University of Bristol in accordance with the requirements of the degree of MSc in Social Work in the Faculty of Law and Social Sciences. School for Policy Studies, September 2009.

Sugaya, L., Hasin, D. S., Olfson, M., Lin, K. H., Grant, B. F., \& Blanco, C. (2012). Child physical abuse and adult mental health: a national study. Journal of traumatic stress, 25(4), 384-392.

Taylor, T. J., Peterson, D., Esbensen, F. A., \& Freng, A. (2007). Gang membership as a risk factor for adolescent violent victimization. Journal of Research in Crime and Delinquency, 44(4), 351-380.

Turner, H.A., Finkelhor, D., \& Ormrod, R.K. (2010). Poly-victimization in a national sample of children \& youth. American Journal of Preventive Medicine, 38, 323-330.

Tjaden, P., \& Thoennes, N. (2000). Prevalence and consequences of male-to-female and female-to-male intimate partner violence as measured by the National Violence Against Women Survey. Violence Against Women, 6(2), 142-161.

Vogeltanz, N.D., Wilsnack, S.C., Harris, T.R,. Wonderlich, S.A., \& Kristjanson, A.F. (1999) Prevalence and risk factors for childhood sexual abuse in women: nation survey findings. Child Abuse \& Neglect. 23(6) 579-592

Williams, D. R., Yu, Y., Jackson, J. S., \& Anderson, N. B. (1997). Racial differences in physical and mental health socio-economic status, stress and discrimination. Journal of Health Psychology, 2(3), 335-351. 
Running Head: Male victimization and mental health

Wolfe, D. A., \& McGee, R. A. (1994). Dimensions of child maltreatment and their relationship to adolescent adjustment. Developmental Psychopathology, 6, 165-181.

Yang, C. (2006). Evaluating latent class analyses in qualitative phenotype identification. Computational Statistics \& Data Analysis, 50, 1090-1104.

Yuan, K.-H., \& Bentler, P. M. (2008). Three Likelihood-Based Methods For Mean and Covariance Structure Analysis With Nonnormal Missing Data. Sociological Methodology, 30(1), 165-200 
Running Head: Male Victimization and Mental Health

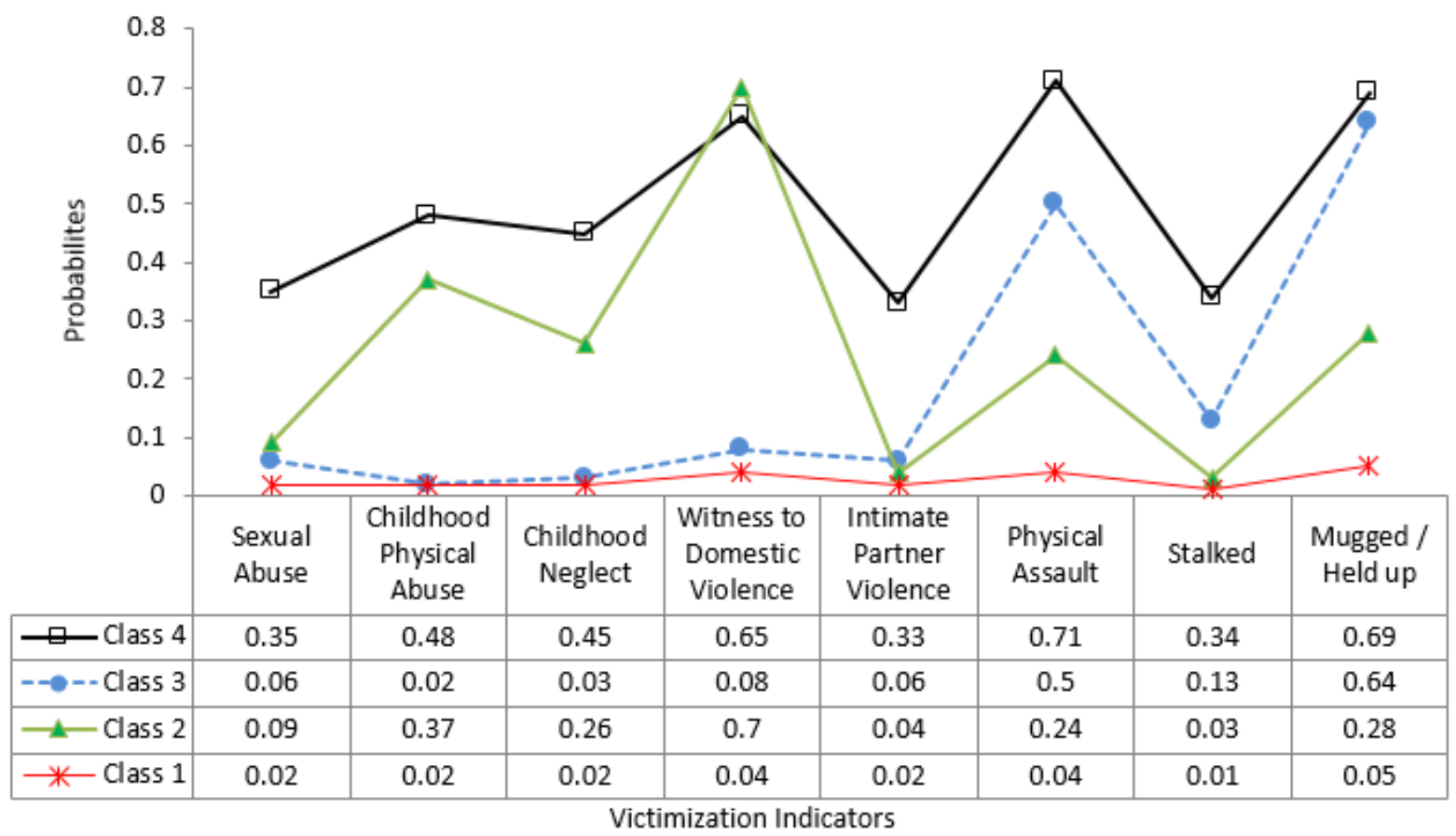

Note; Class 1 = Normative class, Class $2=$ High witnessing of domestic violence $\&$ polyvictimisation class, Class $3=$ Adult victimisation class, Class $4=$ Childhood $\&$ Adulthood polyvictimisation

Figure 1.

Profile plot and probabilities from the latent class analysis of victimization items. 
Running Head: Male victimization and mental health

Table 1. Shows Descriptive Statistics for the Demographic Correlates.

\begin{tabular}{lllllll}
\hline & Age & Caucasian & Black & Hispanic & Other & Low SES \\
\hline M (SD) & $46(18.6)$ & & & & & \\
$\%$ & & $71.3 \%$ & $10 \%$ & $12.3 \%$ & $6.4 \%$ & $3.6 \%$ \\
\hline
\end{tabular}

Note. All percentages are weighted. 
Running Head: Male victimization and mental health

Table 2.

Response rates across victimizations for the male sub-sample of the NESARC

\begin{tabular}{lcc}
\hline Items & $N$ & $(\%)$ \\
\hline Physical abuse & 493 & $3 \%$ \\
Neglect & 418 & $2.7 \%$ \\
Witness to domestic violence & 1347 & $8.9 \%$ \\
Sexual assault & 428 & $2.8 \%$ \\
Intimate partner violence & 345 & $2.1 \%$ \\
Physical assault & 1783 & $12 \%$ \\
Stalked & 430 & $2.7 \%$ \\
Mugged / Held up / Threatened with a weapon & 2528 & $16.4 \%$ \\
Total item endorsement & 4660 & $32.2 \%$ \\
\hline
\end{tabular}

Note. All percentages are weighted. 
Running Head: Male victimization and mental health

Table 3.

Fit Indices for Latent Class Models Two to Six.

\begin{tabular}{lccccc}
\hline Model & AIC & BIC & SSABIC & LRT & Entropy \\
\hline & & & & & \\
2 class & 46061.525 & 46190.391 & 46136.366 & $3878.312 * *$ & 0.766 \\
3 class & 45483.279 & 45680.367 & 45597.741 & $589.41 *^{* *}$ & 0.802 \\
4 class & 45386.524 & 45651.835 & 45540.608 & 113.440 & 0.789 \\
5 class & 45335.608 & 45669.141 & 45529.313 & 68.126 & 0.800 \\
6 class & 45334.238 & 45735.995 & 45567.565 & 19.147 & 0.819 \\
\hline
\end{tabular}

Note: $\mathrm{AIC}=$ Akaike information criterion, $\mathrm{BIC}=$ Bayesian Information Criterion, SSABIC-sample size adjusted BIC, LRT=Lo-Mendell-Rubin adjusted LRT value and associated significance level. $* *=$ significant $\mathrm{p}=<0.001$. 
Table 4. Odds Ratios and (95\% Confidence interval) from the Demographic and Latent Class Variables to General Psychopathology.

\begin{tabular}{|c|c|c|c|c|c|c|}
\hline Items & $\begin{array}{c}\text { GAD } \\
\text { Odds Ratio } \\
(95 \% \mathrm{CI})\end{array}$ & $\begin{array}{l}\text { Depressive disorder } \\
\text { Odds Ratio } \\
(95 \% \mathrm{CI})\end{array}$ & $\begin{array}{l}\text { Manic disorder } \\
\text { Odds Ratio } \\
\text { (95\% CI })\end{array}$ & $\begin{array}{l}\text { Panic disorder } \\
\qquad \begin{array}{l}\text { Odds Ratio } \\
(95 \% \mathrm{CI})\end{array}\end{array}$ & $\begin{array}{l}\text { Social Phobia } \\
\text { Odds Ratio } \\
\text { (95\%CI) }\end{array}$ & $\begin{array}{c}\text { PTSD } \\
\text { Odds Ratio } \\
(95 \% \mathrm{CI})\end{array}$ \\
\hline \multicolumn{7}{|l|}{$\begin{array}{l}\text { Ethnicity } \\
\text { (Reference = Caucasian) }\end{array}$} \\
\hline Black & $\begin{array}{c}0.51 \text { ** } \\
(0.421-0.752)\end{array}$ & $\begin{array}{c}0.57 * * \\
(0.471-0.672)\end{array}$ & $\begin{array}{c}1.32 \\
(0.845-1.287)\end{array}$ & $\begin{array}{c}0.47 \text { ** } \\
(0.335-1.287)\end{array}$ & $\begin{array}{c}0.77 \text { ** } \\
(0.632-0.893)\end{array}$ & $\begin{array}{c}1.10 \\
(0.928-1.474)\end{array}$ \\
\hline Hispanic & $\begin{array}{c}0.54 * * \\
(0.425-0.795)\end{array}$ & $\begin{array}{c}0.67 * * \\
(0.528-0.752)\end{array}$ & $\begin{array}{c}0.94 * * \\
(0.542-0.857)\end{array}$ & $\begin{array}{c}0.56 \text { ** } \\
(0.401-0.857)\end{array}$ & $\begin{array}{c}0.64 * * \\
(0.500-0.718)\end{array}$ & $\begin{array}{c}0.78 \\
(0.672-1.111)\end{array}$ \\
\hline Other Ethnicity & $\begin{array}{c}0.91 \\
(0.697-1.464)\end{array}$ & $\begin{array}{c}0.98 \\
(0.746-1.229)\end{array}$ & $\begin{array}{c}1.29 \\
(0.722-1.405)\end{array}$ & $\begin{array}{c}0.57 * * \\
(0.384-1.405)\end{array}$ & $\begin{array}{c}0.88 \\
(0.647-1.122)\end{array}$ & $\begin{array}{c}0.77 \\
(0.546-1.143)\end{array}$ \\
\hline \multicolumn{7}{|c|}{$\begin{array}{l}\text { Socio-Economic Status } \\
\text { (Reference } \\
=\text { not in receipt of food stamps) }\end{array}$} \\
\hline In receipt of food stamps & $\begin{array}{c}2.55 * * \\
(1.754-3.582)\end{array}$ & $\begin{array}{c}2.18 * * \\
(1.680-2.773)\end{array}$ & $\begin{array}{c}2.70 \text { *** } \\
(2.145-3.875)\end{array}$ & $\begin{array}{c}2.50 * * \\
(1.691-3.875)\end{array}$ & $\begin{array}{c}1.66 * * \\
(1.257-2.135)\end{array}$ & $\begin{array}{c}2.67 * * \\
(2.053-4.003)\end{array}$ \\
\hline \multicolumn{7}{|l|}{$\begin{array}{l}\text { Class membership } \\
\text { (Reference = Class 1) }\end{array}$} \\
\hline Class 4 & $(5.599-11.644)$ & $(5.427-9.899)$ & $(5.359-10.301)$ & (4.791-10.209) & $(2.512-4.702)$ & $(9.108-17.325)$ \\
\hline \multirow{2}{*}{ Class 3} & $2.72 * *$ & $2.91 * *$ & $2.76 * *$ & $3.17 * *$ & $2.40 * *$ & $5.64 * *$ \\
\hline & $(2.080-3.562)$ & $(2.433-3.472)$ & $(2.202-3.460)$ & (2.403-4.181) & $(1.987-2.909)$ & (4.491-7.082) \\
\hline \multirow[b]{2}{*}{ Class 2} & $2.65 * *$ & $3.20 * *$ & $2.77 * *$ & $2.56 * *$ & $2.00 * *$ & $4.37 * *$ \\
\hline & $(1.862-3.759)$ & (2.559-4.008) & (2.114-3.627) & $(1.801-3.645)$ & $(1.575-2.543)$ & (3.286-5.826) \\
\hline
\end{tabular}

Note: $\mathrm{GAD}=$ General Anxiety Disorder, $O R=$ Odds Ratio, $(95 \% \mathrm{CI})=95 \%$ Confidence Intervals, Bold indicates significant $O R$ 's 
Running Head: Male Victimization and Mental Health

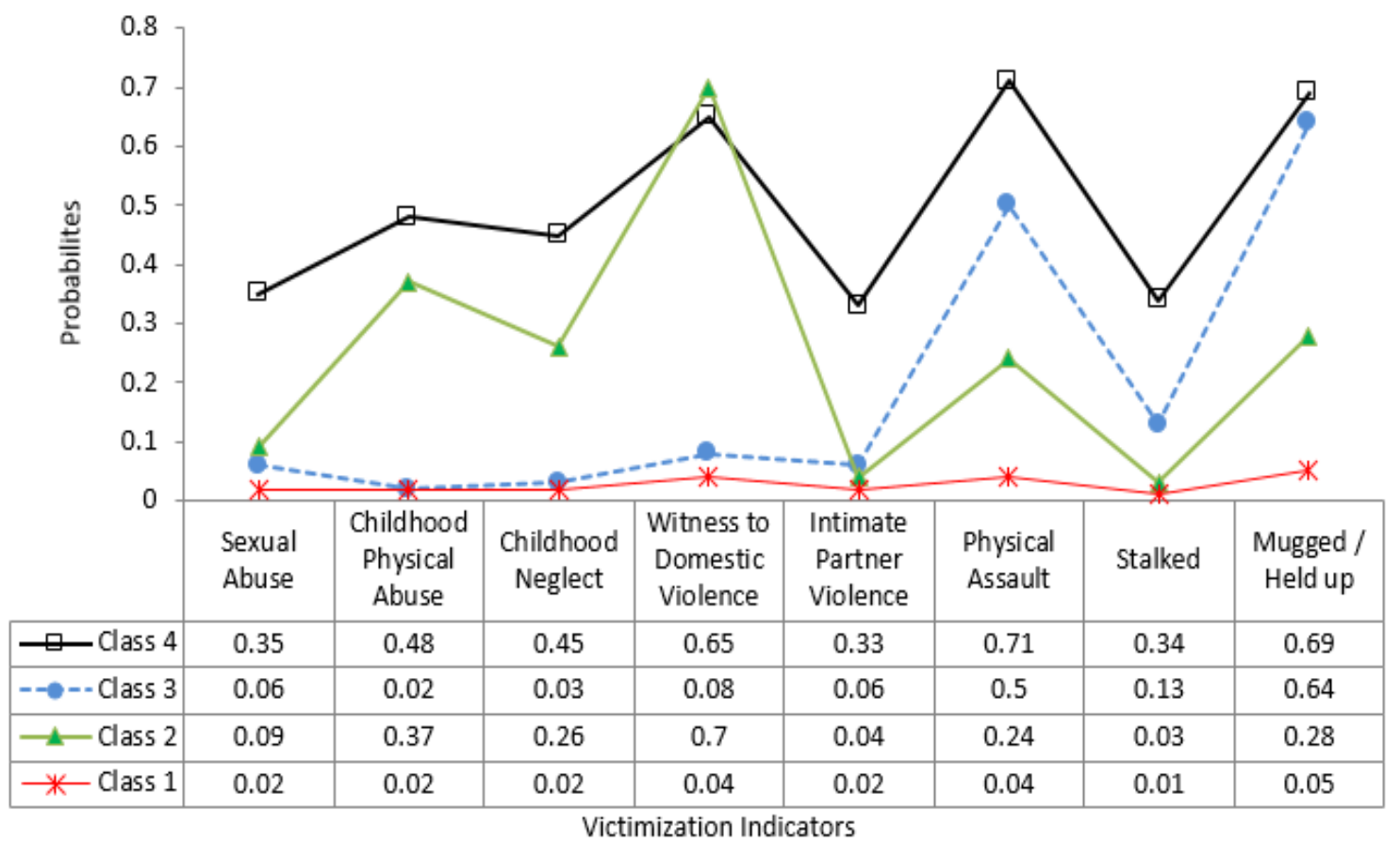

Graphical abstract;

Four latent classes of interpersonal victimisation were uncovered in an exclusively male sample $(N=14,564)$. Class 1 was labelled as a normative class, Class 2 as a high witnessing of domestic violence \& polyvictimisation class, Class 3 as an adult polyvictimisation class, and Class 4 as a childhood \& adulthood polyvictimisation class. Classes 2-4 were compared to class 1 in assessing the comparative risk for psychopathology. Individuals in classes 2-4 had increased odds of reporting a wide range of mental health concerns including PTSD and Generalised Anxiety Disorder. 